\title{
UTILIZAÇÃO DE SISTEMAS DE CUSTOS EM MICRO E PEQUENAS EMPRESAS DE SANTA CATARINA
}

\author{
UTILIZATION OF COSTING SYSTEMS IN MICRO AND SMALL COMPANIES IN \\ SANTA CATARINA STATE, BRAZIL
}

Recebido: 26/09/2017 - Aprovado: 20/10/2017 - Publicado: 30/12/2017

Processo de Avaliação: Double Blind Review

\section{Giovanni Dutra Menegazzo ${ }^{1}$}

Mestre em Administração

Universidade Federal de Santa Catarina

giovannidme@yahoo.com.br

Rogério João Lunkes

Doutor em Engenharia de Produção

Professor da Universidade Federal de Santa Catarina

rogeriolunkes@hotmail.com

\author{
Alcindo Mendes \\ Doutor em Contabilidade \\ Professor da Universidade Federal de Viçosa \\ alcindo.ufv@gmail.com \\ Darci Schnorrenberger \\ Doutor em Engenharia de Produção \\ Professor pela Universidade Federal de Santa Catarina \\ darcisc@gmail.com
}

RESUMO: O objetivo deste estudo consiste em identificar os sistemas de custos mais utilizados em Micro e Pequenas Empresas (MPEs), e as possíveis motivações. Para tanto, elaborou-se um questionário com questões fechadas que foram respondidas por 327 gestores de MPEs do Estado de Santa Catarina (Brasil). Na análise dos dados aplicou-se estatística descritiva e distribuição de frequências. Os resultados mostram que 79,5\% dos gestores afirmam identificar a margem de lucro e aproximadamente $80 \%$ afirma conhecer o ponto de equilíbrio da empresa. Por outro lado, aproximadamente $38 \%$ dos gestores sabem informar se a organização utiliza ou não algum sistema de custeio e dos que sabem, a maioria (74\%), afirma utilizar o custeio variável. Na investigação das possíveis causas constatou-se que o percentual de gestores com formação em áreas afins é bastante próximo ao daqueles que

\footnotetext{
${ }^{1}$ Autor para correspondência: Universidade Federal de Santa Catarina, Campus Reitor João David Ferreira Lima, s/n Trindade, Florianópolis - SC, Brasil, 88040-900
} 
conhecem qual sistema é utilizado, indicando que a formação pode ser um fator explicativo do uso deste tipo de informações. Estes achados podem ser um importante aliado para consulta e orientação de pesquisadores e autoridades responsáveis pelas políticas públicas para as MPEs.

Palavras-chave: sistemas de custeio; micro e pequenas empresas; Brasil.

ABSTRACT: The aim of this study is to identify the cost systems most used in Micro and Small Companies, and the possible reasons for that. Therefore, a survey was elaborated with closed questions on the subject, which were answered by 327 managers of Micro and Small Companies in Santa Catarina State (Brazil). In the data analysis, descriptive statistics and frequency distribution were applied. The results have been shown that approximately $79.5 \%$ of the managers affirm to identify the profit margin and approximately $80 \%$ assure to know the break-even point of the company. On the other hand, 38\% of the managers know whether the organization uses or does not use some costing system, and the most of them (74\%) say they use direct costing. In the investigation of possible reasons, it was found that the rate of managers with formal education in related areas is quite close to those who know which system is used, indicating that formal education may be a reason for the use of this kind of information. These findings can be an important support for the consultation and guidance of researchers and authorities responsible for public policies for Micro and Small Companies.

Keywords: costing systems; micro and small companies; Brazil.

\section{INTRODUÇÃO}

Numa organização há diversos tipos de informações, e entre elas encontram-se as de custos. Também há diferentes níveis de compreensão e utilização dos recursos disponíveis entre as empresas. Kassai (1997) afirma que as MPEs (Micro e Pequenas Empresas), pelas características diferenciadas que apresentam em relação às de médio e grande porte, enfrentam problemas na utilização de práticas gerenciais como, por exemplo, a compreensão dos aspectos financeiros e contábeis do negócio, e a contabilidade de custos. 
De acordo com Vogel e Wood Jr. (2013), embora os proprietários e gestores de pequenas empresas demonstrem consciência sobre a importância das práticas gerenciais para o sucesso do negócio, eles ainda abrem mão de certas práticas consideradas relevantes, seja por desconhecimento, falta de recursos, atitude dos proprietários ou por considerarem a relação custo-benefício desvantajosa. Desta forma, a gestão destas empresas não demonstra ter conhecimentos das funções administrativas, assim como critérios ou conhecimentos de gestão para a tomada de decisão, tornando-se fatores que contribuem com o seu fracasso (SOLOMON, 1986; CHER, 1990; LONGENECKER et al., 1998; HUANG; BROWN, 1999; CÊRA; ESCRIVÃO FILHO, 2003; ALMEIDA et al., 2012).

A não utilização de informações para a tomada de decisões em MPEs pode gerar deficiências, e comprometer inclusive sua sobrevivência no mercado, causando preocupação nos meios político, acadêmico e empresarial (ORTIGARA et al., 2011). Neste sentido, SEBRAE (2013) aponta que aproximadamente 70\% não conseguem superar as dificuldades iniciais e encerram suas atividades nos primeiros três anos e meio de atividade.

A importância da contabilidade de custos para as MPEs, assim como problemas de gestão decorrentes de ineficiências ligadas a informações contábeis, principalmente de custos é evidenciada por vários estudos (RESNIK, 1990; KASSAI, 1997; LONGENECKER et al., 1998; OLIVEIRA; MÜLLER; NAKAMURA, 2000; ZIMMERER; SCARBOROUGH, 2005; STROEHER; FREITAS, 2008; SILVA et al., 2010; NASCIMENTO et al., 2013). Entretanto, boa parte das decisões tomadas é baseada na experiência ou intuição do gestor (LONGENECKER et al., 1998; ALBUQUERQUE, 2004; MORAES; ESCRIVÃO FILHO, 2006; MOREIRA et al., 2013; SANTOS; DOROW; BEUREN, 2016).

Assim, constata-se que há estudos que destacam a importância e utilidade das informações de custos para dar suporte ao processo decisório nas MPEs; mas o seu efetivo uso não se configura em prática habitual. Isso remete à seguinte questão de pesquisa: quais os sistemas de custos mais utilizados pelas MPEs e suas possíveis razões? Assim, o objetivo deste estudo consiste em identificar os sistemas de custos mais utilizados em MPEs, e as possíveis motivações.

Conhecer quais os sistemas de custeio mais utilizados pelas MPEs e as possíveis razões pode trazer importantes contribuições, tanto para a academia, quanto para as próprias organizações. Na academia, estes conhecimentos podem contribuir para direcionar os esforços para produção de conhecimento adaptado a realidade das MPEs, bem como compreender as 
razões das práticas consideradas mais adequadas e que, no entanto, não são utilizadas. Esta compreensão pode resultar em discussões mais focadas nos problemas reais e, consequentemente, evoluir para soluções mais realistas.

\section{REFERENCIAL TEÓRICO}

Nesta sessão são abordados os diferentes sistemas de custos, custeio por absorção, custeio variável e custeio baseado em atividades, bem como a descrição de estudos empíricos sobre a utilização de sistemas de custos em MPEs.

\subsection{SISTEMAS DE CUSTOS}

Determinar os custos de um produto ou serviço, embora possa parecer simples, geralmente consiste em um processo complexo. Há vários métodos de custeio desenvolvidos ao longo da história que podem ser utilizados pelas empresas. Os métodos mais conhecidos e utilizados são: custeio por absorção; custeio variável (também chamado de custeio direto); e o custeio baseado em atividades, também representado pela sigla ABC. Estes sistemas apresentam características particulares, cada um com suas vantagens e desvantagens.

\subsubsection{Sistema de Custeio por Absorção}

No custeio por absorção separa-se os gastos em custos e despesas, sendo que os custos são classificados em diretos e indiretos. Os custos são relacionados à produção de bens e serviços do período e as despesas são lançadas diretamente no resultado do exercício. Martins (2009) descreve que este método também é utilizado para efeito de avaliação de estoques e resultados, sendo todos os custos “absorvidos" pela empresa. A Figura 1 ilustra o custeio por absorção. 
Figura 1 - Custeio por absorção.

Processo de seleção

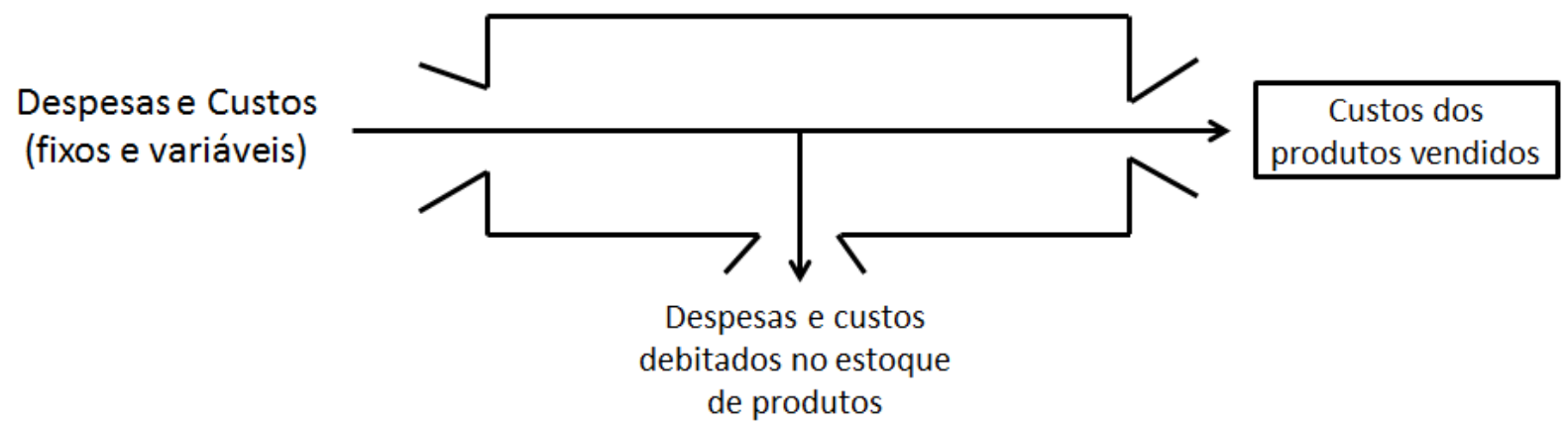

Fonte: Leone (2010).

Kaplan e Cooper (1998) citam, inclusive, que as empresas migraram do sistema de custeio por absorção para o custeio variável justamente em função da natureza arbitrária da alocação dos custos fixos em seu sistema de avaliação de estoques.

\subsubsection{Sistema de custeio direto ou variável e a análise Custo-Volume-Lucro}

Neste sistema, os custos são classificados pela variabilidade, onde há a separação dos custos em fixos e variáveis, sendo fixos aqueles que não dependem do nível de atividade da empresa no curto prazo, ou seja, não variam com alterações no volume de produção, levando à análise do custo-volume-lucro e ao custeio variável, em contraposição ao custeio por absorção.

Tal método determina que os custos fixos são classificados como despesa do período, e contabilizados diretamente no Resultado do Exercício, sem interferir nas margens de lucro dos produtos e mantendo-se constante perante o volume de produção e vendas oscilantes. Portanto, para os estoques só vão os custos variáveis, prática que infringe os princípios contábeis e orientações legais, inviabilizando sua utilização para efeitos externos. Apesar de não ser aceito para fins fiscais, o custeio variável pode ser usado para fins gerenciais, como apoio ao planejamento e tomada de decisões.

Dentro do contexto de separação dos custos, Horngren et al. (1997) alertam para a importância de conhecer como os custos se comportam para entender sua separação, pois muitas funções gerenciais, como planejamento e controle, dependem deste conhecimento. Portanto, separar os custos fixos das variáveis provê informações importantes para a tomada de decisões. 
Perez Jr., Oliveira e Costa (1999) descrevem que o sistema de custeio variável é útil para tomada de decisões administrativas ligadas à flexibilização de preços, decisões de terceirização, determinação do mix de produtos e, ainda, possibilita a determinação imediata do comportamento dos lucros em face das oscilações de vendas. Beulke e Bertó (2012) afirmam ser um sistema com grande grau de aplicabilidade na prática por ser voltado ao mercado, à competitividade, situação comum nas circunstâncias atuais do ambiente econômico. A figura 2 apresenta este sistema:

\section{Figura 2 - Custeio Variável.}

Despesas e Custos

Processo de seleção

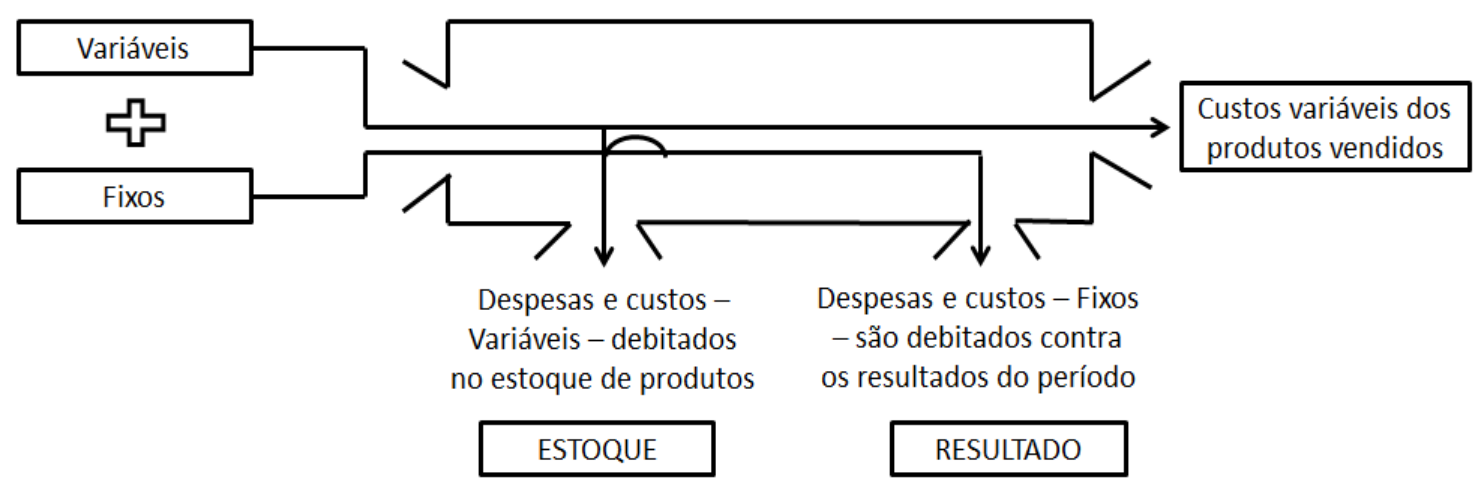

Fonte: Leone (2010).

Após a separação dos custos em fixos e variáveis, seus efeitos sobre receita, volume e lucro podem ser estudados por meio da análise de custo-volume-lucro, abordagem conhecida também como CVL.

Horngren et al. (1997) afirmam que a análise de custo-volume-lucro propicia uma ampla visão financeira do processo de planejamento. Warren, Reeve e Fess (2001) destacam que a análise CVL fornece informações muito úteis para tomada de decisões relacionadas a ajustes de preço de venda, determinação de mix de produtos, definição de estratégias de marketing, análise de efeitos dos custos sobre os lucros. Os autores ainda acrescentam que a análise CVL tem importância crescente por se tratar de um método de análise ágil e preciso, auxiliando os gestores a maximizarem seu tempo e os resultados de suas decisões. Segundo Lunkes (2007), a análise de custo-volume-lucro conduz a dois importantes conceitos: margem de contribuição e ponto de equilíbrio. 
Margem de contribuição é a diferença entre o preço de venda e os custos e despesas variáveis e eventualmente algum custo fixo alocável diretamente ao produto, referentes às unidades vendidas (MARTINS, 2009). Considera-se que os custos fixos não distribuídos são aqueles necessários para operacionalizar os produtos da empresa, e a tomada de decisão se dá através das respectivas margens de contribuição. É a partir da margem de contribuição que se permite conhecer o ponto de equilíbrio de um determinado produto ou mix de produtos da empresa, sendo este um dos itens de interesse dentro da análise do CVL.

O Ponto de equilíbrio corresponde à quantidade produzida/volume de operações para a qual a receita é igual o custo total a fim de determinar o nível de produção em termos de quantidade e/ou de valor que se traduz pelo equilíbrio entre a totalidade dos custos e das receitas (MARTINS, 2009). Para um nível abaixo desse ponto, a empresa estará na zona de prejuízo e acima dele, na zona de lucratividade. A Figura 3 mostra como o ponto de equilíbrio é analisado.

Figura 3 - Análise do ponto de equilíbrio.

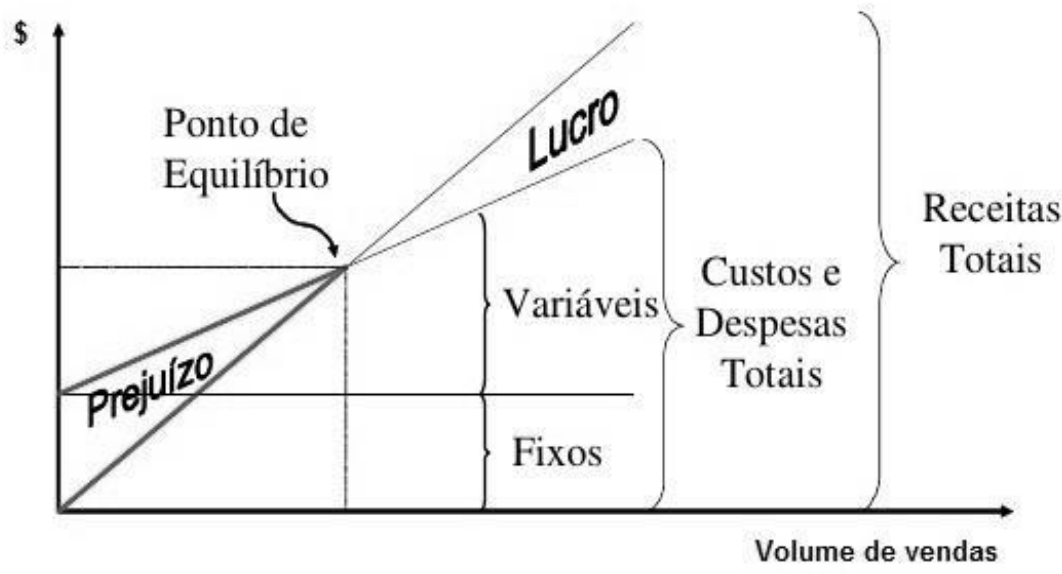

Fonte: Martins (2009).

É importante salientar também as limitações da análise do ponto de equilíbrio. Dentre elas, a maior limitação é o fato do modelo se basear em apenas um produto. Como solução, Horngren et al. (1997) sugerem a utilização de receitas e custos médios para um determinado mix de produtos.

\subsubsection{Sistema de custeio baseado em atividades (ABC)}


Com o aumento da concorrência e a diminuição do uso eficiente da mão-de-obra direta e das máquinas como maiores diferenciais competitivos, Kaplan e Cooper (1998) afirmam que os gerentes precisavam de informações mais precisas sobre os custos dos processos, produtos e clientes do que poderiam obter com os sistemas de relatórios financeiros externos. Martins (2009) explica que a diferença básica do ABC está na procura por reduzir sensivelmente as distorções provocadas pelo rateio arbitrário dos custos indiretos do método de custeio por absorção.

$\mathrm{O}$ método de custeio $\mathrm{ABC}$ é considerado um método de contabilidade gerencial avançado (KAPLAN; COOPER, 1998). Por outro lado, é também o mais dispendioso e exigente para com os envolvidos, desde sua implementação até o controle. Isso dificulta a adoção pelas pequenas empresas, diante da realidade de recursos humanos, financeiros, estrutura e tempo, escassos. Por este motivo, Johnson (1992) e Martins (2009) defendem a ideia de que, dependendo do objetivo da empresa, há casos em que não há necessidade para a sua utilização.

\subsection{ESTUDOS SOBRE SISTEMAS DE CUSTEIO EM MPES}

Vários estudos evidenciam a importância, bem como problemas de gestão decorrentes de ineficiências ligadas a informações relevantes para o apoio à decisão em MPEs. A existência de controles deficientes e a falta de informações úteis para a tomada de decisões faz da contabilidade o instrumento que, se bem utilizada, suprirá a administração de informações a fim de permitir a visualização do desempenho operacional da empresa (OLIVEIRA; MÜLLER; NAKAMURA, 2000).

Dentre as informações financeiras, vale destacar a adoção de métodos de custeio, análises de margem de lucro e ponto de equilíbrio, pois muito das ineficiências em informações financeiras está relacionado ao baixo índice de utilização deste tipo de sistemas em micro e pequenas empresas. Em pesquisa realizada com 45 micro e pequenas empresas, Monteiro e Barbosa (2011) concluíram que a falta de análise das informações e sistema de custos não implantado verificada é preocupante, pois empreendimentos que não utilizam metodologia de avaliação e apuração dos custos podem estar praticando preços abaixo do ponto de equilíbrio, gerando prejuízos contínuos. Isso pode resultar na descontinuidade da organização. 
Stroeher e Freitas (2008) identificaram variáveis, de acordo com contadores e proprietários de pequenas empresas, importantes para seu processo decisório, tais como: ponto de equilíbrio, faturamento, custos, despesas, preço de venda e margem de lucro. Em pesquisa realizada com o objetivo de investigar e relatar as práticas de contabilidade gerencial em 122 indústrias ligadas ao setor de bebidas e alimentos na Grã-Bretanha, Abdel-Kader e Luther (2006) identificaram que 93\% dos respondentes utilizam algum tipo de informação financeira e técnicas contábeis como o sistema de custeio variável (76\%) e análise de Custo-VolumeLucro $(90 \%)$.

Entretanto, o percentual de utilização de práticas gerenciais de custos é menor em empresas de pequeno porte. Num estudo envolvendo 16 micro e pequenas empresas comerciais do Estado de Santa Catarina, Santos et al. (2011) constataram que 56,3\% dos participantes afirmaram conhecer a análise do custo/volume/lucro e ponto de equilíbrio, sendo que apenas 18,8\% aplicam as técnicas. Em estudo realizado por Lunkes (2009), sobre a utilização de informações de custos em 60 empresas hoteleiras (dentre as quais, 59 de micro e pequeno porte) da região de Florianópolis - SC, importante centro de investimento da área de hotelaria, revela que $40 \%$ das empresas utilizam algum sistema de custeio, percentual inferior à pesquisa realizada por Vieira e De Souza (2005) entre doze hotéis de grande porte (resorts) do Sul do País pesquisados, em que se constatou que $83 \%$ utilizam algum tipo de sistema de custeio.

Motta (2000) cita o sistema de custeio variável como o mais adequado para fins gerenciais nas empresas de micro e pequeno portes, em pesquisa realizada no Brasil, afirmação corroborada em recente estudo realizado por Armitage, Webb e Glynn (2016) entre 22 pequenas e médias empresas canadenses e australianas. Os autores verificaram que apesar de haver utilização de informações de custos, a maior parte das empresas utiliza os sistemas de custeio variável (45\%), seguido pelo sistema de custeio por absorção (32\%) e custeio ABC $(14 \%)$.

Dessa forma, vale ressaltar a relevância em buscar uma melhor apuração do universo de micro e pequenas empresas atualmente a partir de uma amostra mais relevante para efeitos comparativos com os estudos citados além de buscar uma melhor compreensão sobre os motivos dos resultados apurados.

\section{METODOLOGIA}




\subsection{DELINEAMENTO DE PESQUISA}

Esta pesquisa é classificada como quantitativa, pois para identificar o uso de sistemas de custos pelas MPEs foram definidos procedimentos sistemáticos para a descrição e explicação dos fenômenos. Richardson (1989) destaca que o método quantitativo caracterizase pelo emprego da quantificação tanto nas modalidades de coleta de informações quanto no seu tratamento por meio de técnicas estatísticas, desde as mais simples, como percentual, média, desvio-padrão, às mais complexas, como coeficiente de correlação, análise de regressão etc.

A pesquisa objeto deste trabalho é descritiva, pois realiza-se o estudo, análise, registro e interpretação dos fatos do mundo físico. Conforme Sampieri et al. (2006), a pesquisa descritiva procura especificar as propriedades, as características e os perfis de pessoas, grupos, comunidades, processos, objetos ou qualquer outro fenômeno que possa ser submetido a uma análise.

Este estudo se dará sob a forma de pesquisa survey, definido por Freitas et al. (2000) como a obtenção de dados ou informações sobre características, ações ou opiniões de determinado grupo de pessoas, indicado como representante de uma população-alvo, por meio de um instrumento de pesquisa, normalmente um questionário.

\subsection{POPULAÇÃO E AMOSTRA}

A pesquisa foi realizada junto aos gestores de 327 MPEs do Estado de Santa Catarina (Brasil), entre os meses de maio e agosto de 2016, compondo assim, a amostra. A escolha dos entrevistados foi por conveniência, em função da dificuldade de acesso a toda população objeto do estudo. As MPEs foram definidas de acordo com o número de trabalhadores, mesmo critério adotado pelo Instituto Brasileiro de Geografia e Estatísticas (IBGE) e Serviço Brasileiro de Apoio às Micro e Pequenas Empresas (SEBRAE) para a classificação do porte de empresas, conforme a Tabela 1: 
REMIPE

Tabela 1 - Classificação das empresas pelo número de empregados.

\begin{tabular}{c|c|c}
\hline \multirow{2}{*}{$\begin{array}{c}\text { Classificação quanto } \\
\text { ao porte da empresa }\end{array}$} & Número de Empregados \\
\cline { 2 - 3 } & $0-19$ & (Comércio/Serviços) \\
\hline Micro & $20-99$ & $10-49$ \\
\hline Pequeno & $100-499$ & $50-99$ \\
\hline Médio & A partir de 500 & A partir de 100 \\
\hline Grande &
\end{tabular}

Fonte: IBGE, 2014.

A Tabela 2 apresenta a o número de empresas respondentes por setor de atividade.

Tabela 2 - Número de empresas por setor de atividade.

\begin{tabular}{c|c|c}
\hline Setor de atividade & Número de empresas & Representatividade \\
\hline Comércio & 171 & $52,3 \%$ \\
\hline Comércio/Serviços & 42 & $12,8 \%$ \\
\hline Indústria & 52 & $15,9 \%$ \\
\hline Indústria/Comércio & 7 & $2,1 \%$ \\
\hline Indústria/Servicos & 1 & $0,3 \%$ \\
\hline Serviços & 54 & $16,5 \%$ \\
\hline Total & $\mathbf{3 2 7}$ & $\mathbf{1 0 0 , 0 \%}$ \\
\hline
\end{tabular}

Fonte: IBGE, 2014.

\subsection{INSTRUMENTO DE PESQUISA}

Para a coleta de dados foi estruturado um questionário composto por questões fechadas relacionadas ao perfil do gestor e o uso e conhecimento sobre o sistema de custeio utilizado, bem como questões sobre a apuração da margem de contribuição e ponto de equilíbrio da empresa.

Antes da aplicação, o questionário passou pela validação de especialistas vinculados ao tema, como professores e consultores, além da realização de um pré-teste com a aplicação do questionário impresso através de visitas pessoais a três empresas para verificar a necessidade de correções ou ajustes nas questões. Após a validação, adotou-se o mesmo 
procedimento junto aos gestores das empresas participantes, realizando entrevistas presenciais com todas elas.

Após a coleta de dados, foi realizada análise exploratória de dados através de estatística descritiva e distribuição de frequências para a identificação do uso de sistemas de custos pelos gestores das MPEs participantes.

\section{RESULTADOS DO ESTUDO}

Este tópico está organizado em duas partes. Na primeira, apresenta-se os dados e resultados encontrados com as respostas dos entrevistados. Na segunda, busca-se realizar uma discussão e cotejamento dos resultados do presente estudo com os obtidos por outros realizados com enfoque similar.

\subsection{APRESENTAÇÃO DOS RESULTADOS}

A primeira questão buscou conhecer a quantidade de empresas e o tipo de sistema de custeio utilizam. Os resultados estão ilustrados no Gráfico 1.

\section{Gráfico 1 - Taxa de utilização dos sistemas de custeio em MPEs.}

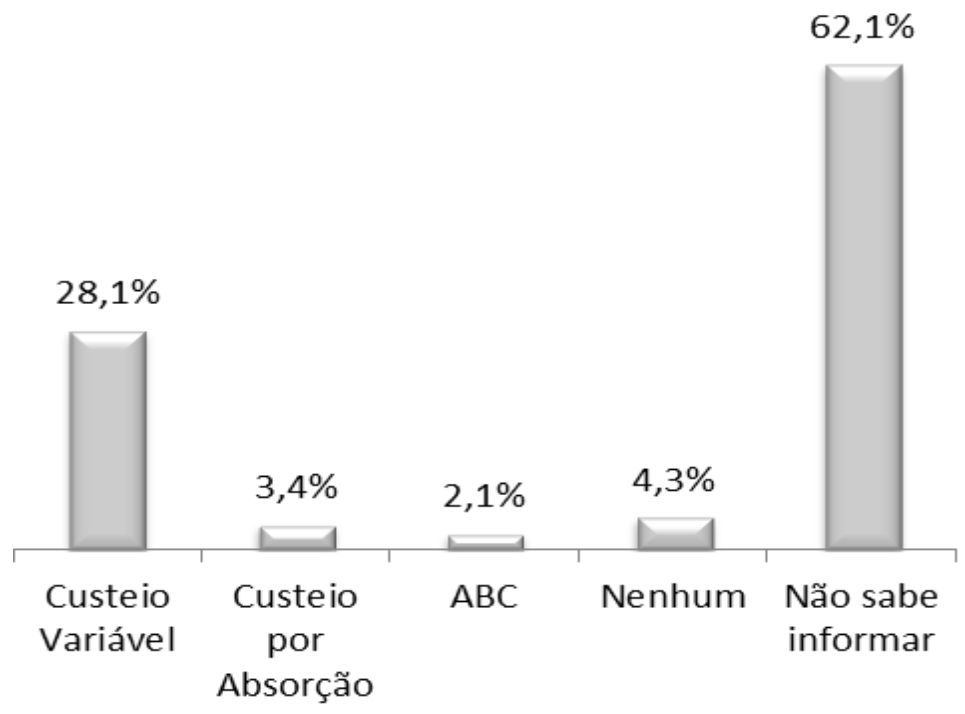

Fonte: Dados da pesquisa (2016).

Conforme destacado no Gráfico 1, é preocupante o fato da maioria dos entrevistados $(62,1 \%)$ não saber informar qual sistemas de custos eles utilizam. Dos que souberam informar $(37,9 \%)$, a maioria $(74,1 \%)$ afirma utilizar o custeio variável. 
Visando aprofundar-se um pouco mais sobre possíveis razões para o baixo uso dos sistemas de custeio, buscou-se conhecer mais sobre a formação dos gestores. O Gráfico 2 apresenta o percentual de gestores que afirmaram possuir algum tipo de formação ou especialização em administração ou áreas afins como ciências contábeis, economia, gestão empresarial, gestão financeira etc.

\section{Gráfico 2 - Formação ou especialização em administração ou áreas afins}

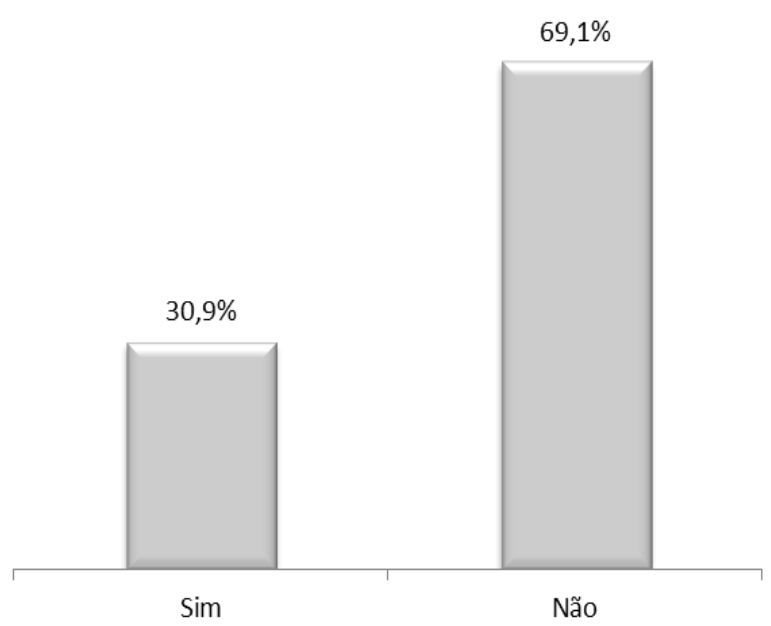

Fonte: Dados da pesquisa (2016).

De acordo com o Gráfico 2, aproximadamente $31 \%$ dos gestores possuem formação ou especialização em administração ou áreas afins, representatividade semelhante à de gestores que afirmam conhecer o sistema de custos utilizado pela empresa. Como se trata de um conhecimento mais específico das áreas de contabilidade e finanças, os percentuais próximos podem ser um indicativo de que aqueles que conhecem e sabem da utilidade dos sistemas de custos, tendem a utilizá-los.

Quando questionados sobre as informações sobre a margem de lucro dos produtos e serviços, os gestores responderam conforme indicado no Gráfico 3. 


\section{Gráfico 3 - Identificação da margem de lucro dos produtos/serviços}

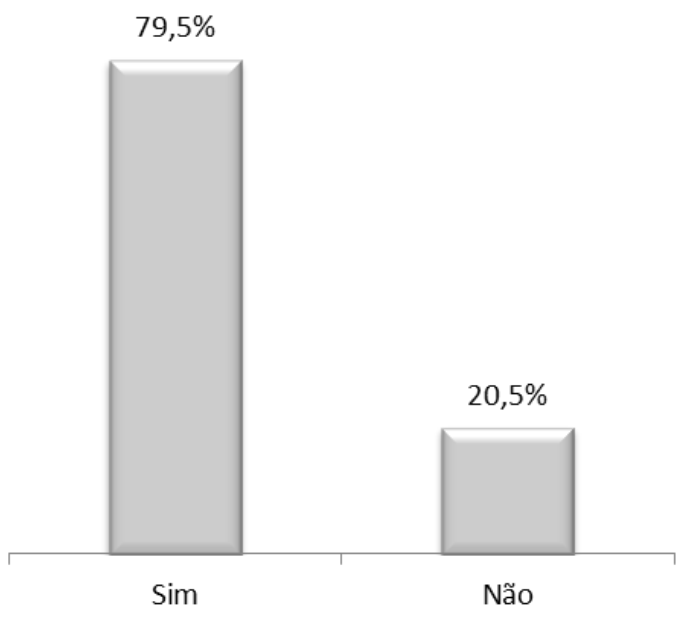

Fonte: Dados da pesquisa (2016).

Do Gráfico 3, pode-se inferir que a maior parte $(79,5 \%)$ dos gestores afirma conhecer a margem de lucro dos produtos da empresa. Isto pode ser considerado um aspecto positivo. Por outro lado, desperta a atenção pelo contrassenso, visto que para conhecer a margem de lucro é necessário identificar, também, os custos.

Seguindo na busca pela compreensão dos tipos de informações que utilizam para tomarem suas decisões, perguntou-se sobre o conhecimento e uso do ponto de equilíbrio. $\mathrm{O}$ Gráfico 4 mostra as respostas a esta questão.

Gráfico 4 - Identificação do ponto de equilíbrio da empresa.

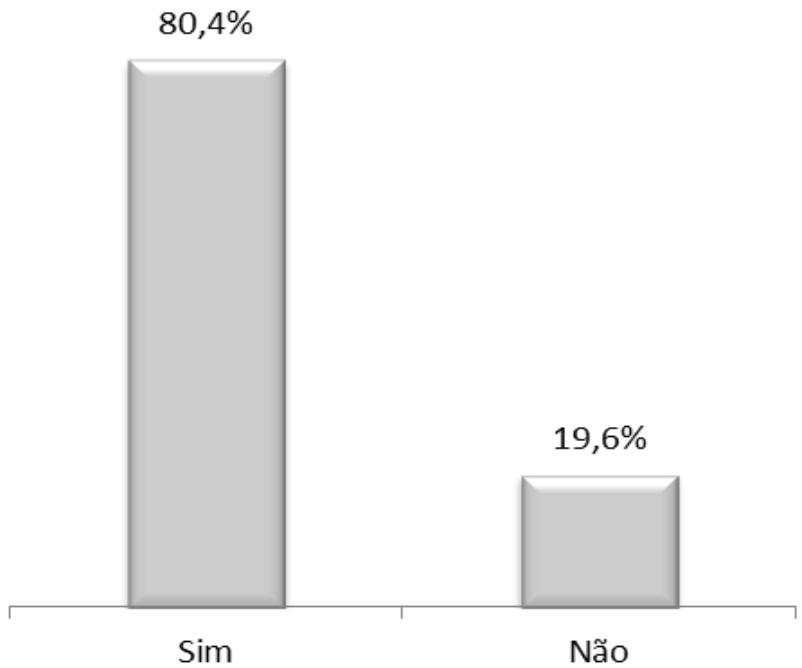

Fonte: Dados da pesquisa (2016). 
Novamente, constatou-se percentual de conhecimento e uso próximo ao verificado no item anterior. Ou seja, aproximadamente $80,5 \%$ dos gestores afirmaram que conhecem o ponto de equilíbrio dos seus produtos e serviços e, por consequência, da organização. Mais uma vez, trata-se de um evento positivo em termos de gestão, porém, curioso sob a ótica da compreensão das causas visto que, novamente requer conhecimentos de custos para ser apurado. Isto pode indicar imprecisão das respostas dos participantes durante a coleta de dados e/ou o uso inconsciente de ferramentas de custos pelos gestores.

\subsection{ANÁLISE E DISCUSSÕES}

O fato de $37,9 \%$ dos gestores saber informar qual sistema de custeio é utilizado pela empresa indica um percentual ligeiramente inferior aos 40\% encontrados por Lunkes (2009). Num primeiro momento, o fato da maioria dos gestores afirmar desconhecer o sistema de custos utilizado pela empresa revela-se ainda um fator preocupante, visto que o seu conhecimento poderia resultar em melhores decisões para suas organizações.

Diante disso, destaca-se o fato de estudos de diferentes culturas, regiões, setores, e períodos ao longo da última década, de modo geral, terem constatado a falta de utilização de análise de informações e uso de sistemas de custos por parte das pequenas empresas.

A constatação de que a maioria $(74,1 \%)$ dos que responderam afirmativamente utiliza o custeio variável (ver Gráfico 1) indica que os achados desta pesquisa corroboram com os estudos de Abdel-Kader, Luther (2006) e Armitage, Webb, Glynn (2016), evidenciando sua preferência e importância, especialmente no universo de pequenas empresas, conforme salientado por Motta (2000).

O fato de que aproximadamente $31 \%$ dos gestores possuem formação em administração ou áreas afins, remete a uma reflexão sobre a existência de uma relação entre os que afirmam conhecer o sistema de custos e a formação. Isso porque, trata-se de um tema que requer conhecimentos específicos e especializados. Esta constatação encontra-se alinhada com os achados de (BECKER, 1970; ROGERS; SHOEMAKER, 1971; KIMBERLY; EVANISKO, 1981; HAMBRICK; MASON, 1984; LI; TAN, 2009), ao atestar que a propensão de uso de ferramentas com maior nível de sofisticação e complexidade administrativa, como sistemas formais de planejamento, complexidade de estruturas, orçamentos detalhados e desempenho da organização está associado ao tipo e nível de 
formação. É possível também traçar um paralelo com a relação entre a escolaridade do gestor e a existência de negócios documentados e planejamento estratégico em pequenas e médias empresas, encontrada por Gibson e Cassar (2002).

Se por um lado a maior parte dos gestores afirmou conhecer a margem de lucro dos produtos e/ou serviços bem como o ponto de equilíbrio das empresas em que atuam, por outro lado, curiosamente, a maior parte afirmou não saber identificar o sistema de custos utilizado pela empresa, ou se a empresa utiliza de fato algum sistema. Estes resultados sugerem que o sistema é utilizado de maneira inconsciente, ou seja, de forma intuitiva. Este aspecto corrobora os estudos que afirmam que boa parte das decisões tomadas é baseada na experiência ou intuição do gestor (LONGENECKER et al., 1998; ALBUQUERQUE, 2004; MORAES; ESCRIVÃO FILHO, 2006; MOREIRA et al., 2013; SANTOS; DOROW; BEUREN, 2016).

\section{CONCLUSÕES}

Lançar um olhar sobre quais informações de custos os gestores de MPEs de Santa Catarina utilizam para tomar suas decisões e verificar possíveis razões, foi o propósito deste estudo. Assim, constatou-se que existe uma aparente contradição nas respostas dos participantes, pois, ao mesmo tempo em que a maioria dos gestores afirma desconhecer o uso de um sistema de custos, a maior parte também afirma fazer uso de práticas que requerem conhecimentos de custos para sua compreensão e utilização.

O baixo índice de utilização ou conhecimento sobre os sistemas de custos indica que a utilização de sistemas que auxiliem os gestores das empresas deste porte a conhecer os seus custos e com base neles tomarem suas decisões, ainda está distante de ser uma prática comum. Isto pode estar atrelado à não adequacidade e confiabilidade das informações geradas, bem como à pouca familiaridade dos gestores com os sistemas contábeis.

Outra razão pode estar associada às características das organizações de porte menor, conforme salientado por Kassai (1997). São empresas nas quais o gestor interage ativa e diretamente com os funcionários, clientes e fornecedores (SOLOMON, 1986). Esta característica, por sua vez, proporciona uma atmosfera mais íntima, a partir de uma aproximação da gestão com os envolvidos (JUDGE; FOWLER, 1994). Em função disso, normalmente os gestores julgam ter menos necessidade de informações financeiras estruturadas por estarem envolvidos em todas as fases das operações, levando-o a decidir com base nas experiências vividas e no feeling. 
Outro aspecto que ficou evidenciado nesta pesquisa é a preferência dos gestores de pequenas empresas pelo Custeio Variável. Isso indica que embora existam métodos mais avançados, o sistema de custeio variável é o mais utilizado pelas pequenas empresas.

O baixo uso ou conhecimento do sistema de custos utilizado pela organização pode ser encontrado no tipo de formação dos respondentes visto que se trata de um tema que requer conhecimentos específicos. Os percentuais próximos entre os gestores que conhecem e utilizam o sistema de custos utilizado pela empresa e os gestores com formação específica, podem ser um indicativo de que aqueles que conhecem e sabem da utilidade dos sistemas de custos, tendem a utilizá-los. Desta forma, o resultado da pesquisa salienta a relevância de cursos específicos e especializados para o aprimoramento técnico do gestor a fim de tornar sua gestão mais eficiente.

Cumpre destacar que estes achados, apesar de terem validade limitada ao público da amostra, podem indicar caminhos a serem seguidos visando aproximar cada vez mais o que é ensinado pela academia e o que é utilizado pelos gestores. São peças do mesmo tabuleiro logo, devem se complementar e não competir.

Vale destacar também algumas implicações observadas no trabalho, como a não identificação da efetividade e a maneira de uso das informações pelos gestores. Para isto, sugere-se a realização de uma coleta de dados mais aprofundada, como, por exemplo, um maior número de perguntas para garantir maior precisão dos dados obtidos, bem como o acesso a informações como registros, sistemas de informações e acompanhamento da rotina do gestor para identificar a frequência de uso, e garantir maior veracidade e precisão das respostas. Todavia, tem-se como grande entrave a limitação de acesso a estas informações num grande número de empresas.

A coleta de dados no horizonte de tempo transversal também implica cautela. Para tanto, tem-se como sugestão coletar os dados referentes a esta pesquisa em diferentes pontos no futuro para uma análise longitudinal, com o intuito de inferir causalidade. Outro ponto a ser observado é o universo da pesquisa, limitado a uma região - Estado de Santa Catarina. Assim, a generalização dos resultados pode exigir uma extensão da análise das construções em outras configurações, tais como diferentes regiões, países e culturas, ou até mesmo maior delimitação de pesquisa, com o intuito de buscar maior profundidade de informações.

Distinções entre MPEs provocadas pela abrangência do setor de atividade e diferenças de recursos disponíveis - financeiros, estruturais ou humanos - são alguns dos 
fatores que podem afetar os resultados da pesquisa. Assim, sugere-se como uma oportunidade para futuros estudos uma maior delimitação quanto ao número de funcionários das MPEs em estudo.

\section{REFERÊNCIAS}

ABDEL-KADER, M; LUTHER, R. Management accounting practices in the British food and drinks industry. British Food Journal, v. 108, n. 5, p. 336-357, 2006.

ALBUQUERQUE, A. F. Gestão estratégica das informações internas na pequena empresa: estudo comparativo de casos em empresas do setor de serviços hoteleiro da região de Brotas. 2004. 209 f. Dissertação (Mestrado em Engenharia da Produção) - Escola de Engenharia de São Carlos da Universidade de São Paulo, São Paulo, 2004.

ALMEIDA, J. et al. A utilização da contabilidade como ferramenta de apoio à gestão nas micro e pequenas empresas do ramo de comércio de material de construção de Feira de Santana/BA. Revista da Micro e Pequena Empresa, v. 6, n. 2, p. 89-106, 2012.

ARMITAGE, H. M; WEBB, A; GLYNN, J. The Use of Management Accounting Techniques by Small and Medium-Sized Enterprises: A Field Study of Canadian and Australian Practice. Accounting Perspectives, v. 15, n. 1, p. 31-69, 2016.

BECKER, M. H. Sociometric location and innovativeness: Reformulation and extension of the diffusion model. American Sociological Review, v. 35, p. 267-304, 1970.

BEULKE. R; BERTÓ, D. J. Estrutura e análise de custos. São Paulo: Saraiva, 2001.

CÊRA, K; ESCRIVÃO FILHO, E. Particularidades de gestão da pequena empresa: condicionantes ambientais, organizacionais e comportamentais do dirigente. EGEPE Encontro de Estudos sobre Empreendedorismo e Gestão de Pequenas Empresas, v. 3, p. 796$812,2003$.

CHER, R. A Gerência das Pequenas e Médias empresas: o que saber para administrá-las. São Paulo: Maltese, 1990.

FREITAS, H; OLIVEIRA, M; SACCOL, A. Z; MOSCAROLA, Jean. O método de pesquisa survey. Revista de Administração, São Paulo v.35, n.3, p.105-112, jul/set., 2000.

GIBSON, B; CASSAR, G. Planning behavior variables in small firms. Journal of Small Business Management, v. 40, n. 3, p. 171-186, 2002.

HAMBRICK, D. C; MASON, P. Upper echelons: the organization as a reflection of its top managers. Academy of Management Review, v. 9, p. 193-206, 1984.

HORNGREN, C. T.; FOSTER, G.; DATAR, S. M. Contabilidade de custos. 9. ed. São Paulo: LTC, c1997. 717p. 
HUANG, X; BROWN, A. An analysis and classification of problems in small business. International Small Business Journal, v. 18, n. 1, p. 73-85, 1999.

JOHNSON, H. T. It's time to stop overselling Activity-Based concepts. Management Accounting, p. 26-35, Sept. 1992.

JUDGE, W. Q.; FOWLER, D. M. A configurational approach to enterprise strategy scope: an upper echelons perspective. International Journal of Value-Based Management, v. 7, n. 2, p. 91-106, 1994.

KAPLAN, R. S. e COOPER, R. Custo e desempenho - Administre seus custos para ser mais competitivo. São Paulo: Editora Futura, 1998. 376p.

KASSAI, S. As empresas de pequeno porte e a contabilidade. Caderno de Estudos Fipecafi, São Paulo, Fipecafi, v.9, n.15, p.60-74, jan./jun. 1997.

KIMBERLY, J. R; EVANISKO, M. J. Organizational innovation: the influence of individual, organizational and contextual factors on hospital adoption of technological and administrative innovations. Academy of Management Journal, v. 24, p. 689-713, 1981.

LEONE, N. As especificidades das pequenas e médias empresas. Revista de Administração da Universidade de São Paulo - RAUSP, São Paulo, v.34, n.2, p. 91-94, abr./maio/jun. 1999.

LEONE, G. S. G. Curso de contabilidade de custos. 4. ed. São Paulo: Atlas, 2010. 458p.

LI, Y; TAN, C. H. Aligning CIO characteristics to business strategy: an empirical investigation. 42nd Hawaii International Conference on System Sciences, Hawaii, USA, 2009.

LONGENECKER, J. G; MOORE, C. W; PETTY, J. W. Administração de pequenas empresas. São Paulo: Makron Books, 1998. 867p.

LUNKES, R. J. Informações de Custos: um estudo em empresas hoteleiras na cidade de Florianópolis - SC. Turismo em Análise, da Universidade de São Paulo, v.20, n.2, agosto 2009.

LUNKES, R. J. Contabilidade gerencial: um enfoque na tomada de decisão. Florianópolis: Visual Books, 2007. 256 p.

MARTINS, Eliseu. Contabilidade de custos. 9. ed. São Paulo: Atlas, 2009. 376 p.

MONTEIRO, J. M; BARBOSA, J. D. Controladoria empresarial: gestão econômica para as micro e pequenas empresas. Revista da Micro e Pequena Empresa, Campo Limpo Paulista, v.5, n.2, p. 38-59, mai./ago, 2011.

MORAES, G. D. de A; ESCRIVÃO FILHO, E. A gestão da informação diante das especificidades das pequenas empresas. Ci. Inf., Brasília, v. 35, n. 3, p. 124-132, set./dez. 2006. 
MOREIRA, R. de L. et al. A importância da informação contábil no processo de tomada de decisão nas micro e pequenas empresas. Revista Contemporânea em Contabilidade, vol. 10, n. 19, p. 119-140, 2013.

MOTTA, F.G. Fatores condicionantes na adoção de métodos de custeio em pequenas empresas: estudo multicaso em empresas do setor metal-mecânico de São Carlos-SP. Dissertação de Mestrado em Engenharia de Produção, Universidade de São Paulo, Brasil, 2000.

NASCIMENTO, et al. Fatores determinantes da mortalidade de micro e pequenas empresas da região metropolitana de Florianópolis sob a ótica do contador. R. eletr. estrat. neg., Florianópolis, v.6, n.2, p. 244-283, mai./ago. 2013.

OLIVEIRA, A. G.; MÜLlER, A. N.; NAKAMURA, W. T. A utilização das informações geradas pelo sistema de informação contábil como subsídio aos processos administrativos nas pequenas empresas. Revista da FAE, Curitiba, v.3, n.3, p.1-12, set./dez. 2000.

PEREIRA, H. J; SANTOS, S. A. dos. Criando seu próprio negócio. Brasília: Sebrae, 1995. $316 p$.

PEREZ JUNIOR, J. H; OLIVEIRA, L. M. de; COSTA, R. G. Gestão estratégica de custos. São Paulo: Atlas, 1999.

QUEIROZ, L. M. N. de. Investigação do uso da informação contábil na gestão das micro e pequenas empresas da região do Seridó Potiguar. Dissertação de Mestrado. Universidade Federal do Rio Grande do Norte. Natal, 2005.

RESNIK, P.. A bíblia da pequena e média empresa. São Paulo: Makron Books, 1990. 280p.

RICHARDSON, R. J; PERES, J. A. de S. Pesquisa social: métodos e técnicas. 2. ed. ampl. São Paulo: Atlas, 1989. 286p.

ROGERS, E. M; SCHOEMAKER, P. Communication of innovations. New York, Free Press, 1971.

SAMPIERI, R. H; COLLADO, C. F; LUCIO, P. B. Metodologia da Pesquisa. Trad: Fátima Conceição Murad, Melissa Kassner, Sheila Clara Dystyler Ladeira. 3. ed. São Paulo: McGraw-Hill, 2006.

SANTOS, V. dos et al. Instrumentos da Contabilidade Gerencial utilizados em micro e pequenas empresas comerciais e disponibilizados por empresas de serviços contábeis. Revista Catarinense da Ciência Contábil, v. 8, n. 24, p. p. 41-58, 2011.

SANTOS, V. dos; DOROW, D. R; BEUREN, I. M. Práticas gerenciais de micro e pequenas empresas. Revista Ambiente Contábil, v. 8, n. 1, p. 153, 2016.

SILVA, D. J. C. da; MIRANDA L.C; FREIRE, D. R; ANJOS; L. C. M. dos. Para que serve a informação contábil nas micro e pequenas empresas. Revista Contemporânea de Contabilidade v. 7, n. 13, p. 89-106, 2010. 
SOLOMON, S. A grande importância da pequena empresa: a pequena empresa nos Estados Unidos, no Brasil e no mundo. Rio de Janeiro: Nórdica, 1986. 408p.

STROEHER, A. M; FREITAS, H. O uso das informações contábeis na tomada de decisão em pequenas empresas. Revista de Administração Eletrônica RAUSP-e, São Paulo, v. 1, n. 1, p. $1-25,2008$.

VIEIRA, W. Q; DE SOUZA, M. J. B. Gestão de custos nos hotéis de lazer da região sul do Brasil. Turismo-Visão e Ação, v. 7, n. 3, p. 427-438, 2005.

VOGEL, J; WOOD JR, T. Práticas gerenciais de pequenas empresas industriais do Estado de São Paulo: um estudo exploratório. REGEPE-Revista de Empreendedorismo e Gestão de Pequenas Empresas, v. 1, n. 2, 2013.

WARREN, Carl. S; REEVE, James M; FESS, Philip E. Contabilidade Gerencial. São Paulo: Pioneira Thomson Learning, 2001.

ZIMMERER, T.; SCARBOROUGH, N. M. Essentials of entrepreneurship and small business management. 4. ed. New Jersey: Pearson Prentice Hall, 2005. 